
3 Research Square
Preprints are preliminary reports that have not undergone peer review.
They should not be considered conclusive, used to inform clinical practice,
or referenced by the media as validated information.

\title{
Self-Regulated Learning versus Activity-based Intervention to Reduce Behavioral Problems and Enhance School-related Function for Children with Autism Spectrum Disorders: A Randomized Control Trial
}

\author{
Farahiyah Wan Yunus \\ Universiti Kebangsaan Malaysia \\ Michelle Bissett \\ Griffith University - Gold Coast Campus \\ Stefania Penkala \\ Western Sydney University \\ Masne Kadar \\ Universiti Kebangsaan Malaysia
}

Karen P.Y. Liu ( $\square$ karen.liu@westernsydney.edu.au )

Western Sydney University https://orcid.org/0000-0001-7397-5149

Research article

Keywords: Active learning, Cognitive Approach, Activity-based, Behavior, School function

Posted Date: August 9th, 2019

DOI: https://doi.org/10.21203/rs.2.11561/v1

License: (c) (i) This work is licensed under a Creative Commons Attribution 4.0 International License. Read Full License 


\section{Abstract}

Background: Self-regulated learning is an active learning cognitive approach which helps individuals to be aware of their own ability and environment and control their own learning. This study examined the therapeutic effects on reducing behavioral problems and enhancing school-related function in children with Autism Spectrum Disorders. Methods: Forty children (aged 6-12) were randomized into a 12-week self-regulated learning or activity-based group. Three outcome measures, assessing the behavioral problems and school-related function, were administered before and after the intervention and at one-month follow-up. The results between the two groups were also compared using two-way repeated measure multivariate analysis of variance tests. Results: Children in the self-regulated learning group reported a significant reduction in 'Maladaptive Behavior'. Both groups showed better school-related function after the intervention with greater improvement found in the self-regulated learning group including 'Functional Communication', 'Memory and Understanding' and 'Positive Interaction'. In the one-month follow-up, the self-regulated learning group showed significant better results in the 'Maladaptive Behavior' in addition to the 'Functional Communication', 'Memory and Understanding', 'Following Social Conversations', 'Positive Interaction' and 'Behavior Regulation' in the school-related function. Conclusions: The self-regulated learning and activity-based interventions are effective in enhancing school-related functions. In addition, the self-regulated learning intervention is effective in reducing behavioral problems of children with ASD. The SRL intervention was seen to be effective compared to the activity-based intervention with particular benefits for ongoing learning and improvements. Trial registration: ClinicalTrials.gov, NCT02496819. Registered 14 July 2015.

\section{Background}

There is an increasing report of children with Autism Spectrum Disorders (ASD) with 100-250 per 10,000 reported in an international study in 2013 (1). According to the Diagnostic and Statistical Manual of Mental Disorders (5th edition) (DSM-5) (2), people with ASD have difficulties in two key areas: i) restrictive and repetitive patterns of behaviors, interests or activities; and ii) difficulties with social interactions and social communication. Behavioral problems in children with ASD do not only affect their social interactions and communication but can also limit their participation in daily activities such as engagement in school work (3).

Behavioral problems consist of internalizing and externalizing behaviors. Internalizing behaviors are behaviors that are inner-directed and over controlled (4). Symptoms of internalizing behaviors include depression, anxiety, nervousness, social isolation, withdrawal, shyness, poor eye contact and lack of interest in life activities $(5,6)$. Conversely, externalizing behaviors are problems that have negative effects on the external environment (7). Symptoms of externalizing behaviors include impulsiveness, disruptiveness, hyperactivity, difficulty in selfcontrol, temper tantrums, intentionally disobeying instructions, inconsiderate or insensitive interactions towards others, physical aggression, stubbornness and inappropriate behavior in public $(6,7)$.

Interventions which directly address participation in daily and school activities in children with ASD are limited (8). Intensive behavioral intervention as part of the Applied Behavioral Analysis approach is a commonly used intervention approach (9) which involves identifying children's behavioral problems and applying positive and negative reinforcement to enhance positive responses. The Applied Behavioral Analysis approach has the strongest research evidence in reducing behavioral problems. Intensive behavioral intervention can be intensive, involving discrete-trial reinforcement-based teaching. For example, in the study by Reed, Osborne (10), the intervention was delivered on a one-to-one basis for a range of 12 to 40 hours a week over 9 to 10 months. Given the time commitments required, the interventions require support and involvement from the child's family and people around them. This approach is usually implemented in children less than five years old (11). Video modeling is another commonly used behavioral intervention in which children are asked to imitate the behavior performed by a model in a natural setting (12). Video modeling is often used to focus on the social domain of targeting socially relevant behaviors (13). There is a lack of research showing the effects on enhancing children's school-related function such as task completion, communication and compliance to instructions during their participation in daily school activities due to behavioral problems using these two commonly used interventions.

Self-regulated learning (SRL) has been shown to enhance individuals' participation in daily activities as a result of underlying psychological, cognitive or sensory-motor problems (14-16). SRL originates from Albert Bandura's social-cognitive theory (17), involving self-monitoring and self-modification of one's behavior (18). Using a cognitive approach, the SRL is an active learning strategy which helps the individual to be aware of their own ability and environment and control their own learning. This is achieved by the person monitoring their own performance, identifying their own solutions and reflecting on their success $(15,16,19)$. Lamb, Bibby $(19)$ found that children with learning disabilities improved in reading and Intelligent Quotient (IQ) levels after applying a SRL approach. Hahn-Markowitz, Manor (20) also found improvement in the behavior of children with attention deficit hyperactive disorders after implementing SRL. Liu and Chan (15) found that SRL facilitated increased performance in daily tasks (i.e. folding laundry, preparing cups of tea, washing dishes) which demanded both motor and cognitive abilities in people with stroke. With the positive evidence of SRL on enhancing performance and 
participation in daily activities, the use of SRL on children with ASD is warranted. Furthermore, there is a lack of research on using a cognitive approach to enhance school-related functions in children of ASD.

\section{Methods}

This study aimed to investigate the effectiveness of a SRL intervention in reducing behavioral problems and enhancing school-related function in children with ASD by comparing it with an activity-based intervention as the control intervention. The authors hypothesized that, by using a cognitive approach, the SRL intervention would reduce behavioral problems and enhance school-related function in children with ASD.

\section{Study design and study setting}

This study was conducted as a single-blind randomized controlled trial (RCT) at the National University of Malaysia's Occupational Therapy Clinic using a SRL intervention as the experimental group and an activity-based intervention as the control group.

Separate rooms were organized for each of the interventions to minimize the cross-contamination of interventions.

\section{Participants}

Forty children with ASD ranging in age from six to 12 years participated in the study. All of the children were required to have: (i) diagnose of ASD by a pediatrician in accordance with the DSM-5 criteria, (ii) an overall raw score of greater than 10 on the maladaptive behavior index of the Vineland Adaptive Behavior Scale, Second Edition (VABS-2) exhibiting some forms of undesirable behaviors (6), and (iii) IQ of 50 or more, indicating a moderate, mild grade of intellectual disability or normal intelligence. Children were excluded if they had been diagnosed with Asperger syndrome or had any other pervasive developmental disability or dual diagnosis as noted by the pediatrician. Children who did not attend school or were home schooled were also excluded. The children were recruited through an initial advertisement with contact details of the researchers distributed at local centers and schools in Malaysia. The study was granted ethical approval from the Western Sydney University Human Ethics Committee (H10816), the Economic Planning Unit of the Prime Minister's Department of Malaysia (UPE: 40I200I19/3128) and the National University of Malaysia (NN-162-2014).

\section{Procedure and randomization}

The study was conducted at the National University of Malaysia's Occupational Therapy Clinic. Participants was recruited from the clinic and outside the clinic as promotion flyers to recruit potential participants were posted both within and outside the setting. Potential participants were screened based on the selection criteria. The parents of the children were provided with an information sheet and the study was explained to them verbally, providing an opportunity for them to discuss any concerns prior to providing written consent. Once consent was obtained, the children were randomly allocated to one of the two groups. Randomization was completed using a computergenerated randomization table (21). A qualified occupational therapist, employed as a research assistant, completed the relevant assessments. This therapist was blinded to the assignment of the participants' group allocation. The occupational therapists running the intervention and the parents could not be blinded to the type of intervention allocated to the participants; however, they were blinded as to which intervention was the control and which was the experimental intervention.

\section{Outcome measures}

Three assessments were used to measure behaviors and school-related functions of children with ASD. These were the: (i) Vineland Adaptive Behavior Scale, Second Edition (VABS-2) (6), (ii) the Behavior Rating Inventory of Executive Functions (BRIEF) (22) and (iii) School Function Assessment (SFA) (23).

The VABS-2 is a commonly used assessment to assess behavioral problems. It is reported to have good internal consistency ( $a \geq 0.75$ ), test-retest reliability (ICC $=0.72-0.84)$ and inter-rater reliability (ICC $=0.81-0.83)(6)$. The Maladaptive Behavior Index of the VABS-2 was used to assess the internalizing and externalizing behaviors of the children in the study. The BRIEF has previously been used to assess 
executive function behaviors in home and school environments with good internal consistency $(a=0.80-0.98)$ and test-retest reliability (ICC = 0.76-0.85) (22). It is a parent-rated measure and has been validated for use in Malaysian parents (24). The Behavior Regulation Index and the Metacognitive Index of the BRIEF were used in this study. The SFA was designed to assess primary-school student participation in various school-related activities. The SFA - Part III: Activity Performance - Cognitive/ Behavior Tasks were adopted in this study to assess the children's ability to initiate and complete specific functional activities while assessing the cognitive/behavior of each task given. This reflects the children's school-related functioning. The SFA is reported to have good internal consistency $(a=0.92-0.98)$ and test-retest reliability (ICC $=0.82-0.98)(23)$.

The VABS-2 and the SFA were rated by the research assistant. As the BRIEF is a parent-rated assessment on the children's performance, it was completed by respective parents. Assessments were carried out three times: at pre-intervention, post-intervention and one month after post-intervention for follow-up.

\section{Experimental intervention: Self-regulated learning}

The SRL intervention consisted of a 12-week program of one 60-minute session per week. The SRL intervention consists of 15 daily and school tasks with nine steps (Figure 1). The intervention was delivered by a pediatric occupational therapist. The intervention is an one-toone intervention between the child and the therapist.

The SRL intervention begins with the child watching a video of a task performance that has been created using a healthy adult person as a model (Step 1). The steps involved in each of the tasks and the video recorded have been validated and approved by an expert panel for use in this study. All children watch the same set of videos. Upon watching the video, the child is required to name the steps involved in the task [for example, organizing backpack for school] (Step 2) and is instructed to name the steps to be performed [including choosing books required for the day, taking pencil case, putting them in the backpack] (Step 3). The intervention continues with the child performing the task and the performance is videotaped (Step 4). The child then identifies the problems made in his or her own attempt at the task by reviewing the recorded performance and comparing it with the example video shown earlier [for example, missing one of the books required for the day] (Step 5). The child engages in finding appropriate solutions for the problems [checking timetable for the day to make sure all books required are packed] (Step 6). The child then performs the task using the discovered solution(s) and the performance is again videotaped (Step 7). Playback of the recorded performance is repeated to induce an evaluation of the effectiveness of the self-identified solution until the child finds a suitable solution for the problem (Step 8). The child then practices the rectified task performance until they demonstrate competence in performing the daily task (Step 9). The child is guided by the therapist throughout the process. The same procedure continues with each of the 15 daily and school tasks.

\section{Control intervention: Activity-based}

The frequency and duration of the activity-based intervention (control) was consistent with the SRL intervention. It was implemented by another trained occupational therapist. The activity-based intervention focused on three main activities: i) construction, ii) drawing and iii) crafts. The program consisted of a 20-minute construction activity, a 15-minute drawing activity, five minutes rest and a 20-minute craft activity. The intervention followed Pfeiffer, Koenig (25) fidelity criteria for implementing interventions. This consisted of: (i) providing appropriate support to ensure the completion of tasks, (ii) creating interventions based on the therapeutic needs of the child, (iii) using interventions based on the children's interests to maintain attention and focus on tasks and (iv) enabling adjustable seating and positioning for the children in response to their specific sizes and needs.

\section{Data analysis}

Statistical analyses were performed based on intention to treat principles and missing data was substituted using last observation carried forward. Data was analyzed using SPSS version 22. Descriptive statistics were used to report the demographic characteristics of the sample. Pearson's Chi Square and one-way Analysis of Variance (ANOVA) were used to check for baseline differences between the intervention and control group. The differences in the assessments from the three time points (pre, post, follow-up) for all participants were analyzed using repeated measures Multivariate Analysis of Variance (MANOVA). The results between the two groups were also compared using two-way repeated measure MANOVA. Post-hoc Tukey tests were used to identify the differences, if any, between all possible pairs. The significance level was set at a two-tailed $p<0.05$ for all comparisons. The partial eta squares were reported to indicate the effect sizes 
in the within-group comparison. The partial eta square of 0.01 indicates a small effect size, 0.059 denotes a medium effect size and 0.138 reveals a large effect size $(26,27)$.

\section{Results}

The consolidated standards of reporting trials (CONSORT) flow diagram for the transparency of randomization was used in this study (Figure 2).

Of the 56 participants enrolled, 16 participants did not meet the selection criteria. All 40 participants who fulfilled the selection criteria were recruited. Twenty 20 participants were allocated to each of the groups. A small number of dropouts $(n=3)$ occurred in the control intervention group. Dropouts were due to participants moved to another therapy center or area and/or parents unable to commit to the 12week intervention program. No dropouts were reported in the follow-up stage of the study.

The majority of the participants were male $(n=34,85 \%)$ with an average age of $7.57(S D=1.34)$. Their primary cultural background was Malay $(n=34,85 \%)$, with Islam being their main religion $(n=34,85 \%)$. The majority of children attended primary school $(n=28,70 \%)$ with slightly more attending special education classes $(n=23,57.5 \%)$. More than half of the participants $(77.5 \%)$ had either mild $(n=11)$ or moderate $(n=20)$ intellectual disabilities. Almost all of the children $(n=39,97.5 \%)$ were receiving, or had received, a mixture of both occupational therapy, speech therapy and physiotherapy, with about half of them receiving weekly therapy ( $n=18)$. The mean VABS-2 score was 18.22, indicating that the children experienced problem behaviors related to internalizing, externalizing and other types of undesirable behaviors that interfered with the individual's adaptive functioning. These demographic characteristics were comparable between groups (Table 1) and no statistical significance was identified except for IQ $(p=0.04)$. However, the numbers of children with normal intelligence between the control and experimental groups were comparable ( $\mathrm{n}=5$ and 4 respectively).

The results of ANOVA also showed no significant difference in the baseline measures between the two groups (Table 2).

For the within group comparisons, the repeated measure MANOVA (Table 3) at the three time points (pre-post-follow-up) indicated a significant difference in the VABS-2 and BRIEF in both the SRL (all $p s \leq 0.001$ ) and the activity-based group ( $p s=0.01$ to 0.04 ). The SFA results demonstrated three items were significantly different in the activity-based group ( $p s \leq 0.01)$ and eight items were significantly different in the SRL group ( $p s=0.00$ to 0.05 ). Post hoc Tukey pre-post tests showed 10 items were significantly improved in the SRL group compared to only four in the activity-based group (Table 3). Reviewing the effect size at pre- and post-interventions also showed a greater effect of the SRL group in 11 out of 12 items when compared to the activity-based group.

For the between group comparisons, the SRL group showed a significant better improvement that the activity-based group post intervention for 'Functional Communication', 'Memory and Understanding' and 'Positive Interaction' in the SFA (Table 2). In the post-intervention and follow-up, the SRL group showed significant better results in the 'Maladaptive Behavior Index' in the VABS-2 in addition to the 'Functional Communication', 'Memory and Understanding', 'Following Social Conversations', 'Positive Interaction' and 'Behavior Regulation” in the SFA.

\section{Discussion}

Improvements were shown in both the SRL and the activity-based groups with greater improvements reported in the SRL group in both behaviors and school-related function. The SRL intervention was more effective in reducing maladaptive behavior and enhancing schoolrelated function. As the SRL intervention requires self-reflection, the strategy of enabling children to see their own performances in the video playback may have increased their self-confidence in the respective tasks (19, 28-30). Morgan and Salzberg (12) and Powers and Handelman (31) evidenced the importance of self-reflection by using videos to monitor performances and provide reflection; they found that this strategy increased the confidence of learners throughout the sessions. This study also demonstrated a similar result using selfreflection. Increasing confidence levels arising from this self-reflection might enhance children's self-esteem, which can lead to improved school-related function such as understanding others' behaviors, communicating and interacting with peers as indicated in the results of this study. These findings are similar to those in Hahn-Markowitz, Manor (20), whose study reported organized and controlled behavior in 
children with attention deficit hyperactive disorder after they received this cognitive-functional intervention. It further strengthens our hypothesis that the cognitive approach used in the SRL intervention can foster self-awareness, active and self-directed learning in children, which contributes to positive outcomes.

A significant reduction in maladaptive behaviors, as indicated in the results of the VABS- 2 and the BRIEF, was observed in children who received the SRL intervention. This reduction may have been proportional to the changes in their levels of self-awareness $(19,32)$. Previously, they may not have understood that their behaviors were inappropriate. Watching footage of their behavior may be a powerful tool to enable children to self-reflect when learning new behaviors and improving existing ones (33). Therapist guidance, hints and the manipulation of the video playback using pauses, rewinding and slowing down ensure that the children self-detect their undesirable behaviors. The results of our study align with the findings that the SRL intervention is applicable and is effective for children with moderate and mild intellectual disabilities. The extent of such improvement in maladaptive behaviors was not observed in the activity-based group.

Children in the SRL group demonstrated enhanced school-related function such as communication, understanding others, compliance with adult directives and school rules, task completion and awareness of safety as shown by the SFA results. Besides self-reflection and given the advantage to attend to and watch numerous performances and to respond to the video in the SRL intervention, the children's attention to their problems may have been improved (34). Studies have suggested that children with ASD tend to pay selective attention to television and spend a large proportion of time at home watching television as they learned better from visual learning $(35,36)$. This is somewhat similar to using video playback as a reflective tool that could be beneficial to the learning in children with ASD. In the activity-based group, children participating in the intervention also exhibited improved understanding, compliance with adult directives and school rules and completion of tasks. There was no significant difference with children in the SRL group in their ability to comply with adult directives and school rules and in the completion of tasks. Children in both groups were required to follow instructions and complete different tasks. The nature of the two interventions is a possible reason for the improvement in their compliance and task completion. In terms of attention to tasks in the activity-based group, it is proposed that attention is required during the craft activities in the activity-based intervention. This proposition was similar to the findings reported by Legoff (37) who found increased attention capabilities in children who played with Lego blocks. Miller, Coll (38) also reported a slight improvement in attention and a slight reduction of problem behaviors after implementing activities consisting of arts, crafts, puzzles and blocks and reading stories and playing interactive games.

Tasks in the SRL intervention typically focused on daily and school-related actions that children perform in everyday life. Therefore, the children received the SRL intervention might have enhanced school-related functions. These findings concur with previous studies $(15,16$, 39) that demonstrated an improvement in daily functioning after self-regulation had been implemented. Learning skills, while monitoring difficulties and applying problem-solving strategies, assists with improving self-awareness and motivation to learn, leading to success in task performance.

There are several limitations in this study. Firstly, the SRL intervention focused on tasks related to daily activities and school functioning; therefore, the improvement seen in the SFA may be a consequence of the practices offered by this group that were not provided by the activity-based group. This creates a potential bias in the study. Secondly, the children with ASD included in the study had normal to moderate intellectual abilities and were recruited within a particular center. It is not known whether the intervention could be applied to children with more severe intellectual abilities and whether the results and effectiveness would remain the same. Therefore, our study results may not be generalized to all children with ASD. Thirdly, no restrictions were placed on participants not to engage in other types of interventions outside of the study. This might have influenced the improvements observed.

Future research is suggested to investigate the use of SRL in children with different cognitive abilities. In addition, SRL interventions could be utilized for different tasks and may be implemented in other settings beyond schools. Other daily tasks such as money management, shopping and the use of public transport could benefit from exploration by future studies promoting community living skills and transition to adulthood.

\section{Conclusions}

The SRL and activity-based interventions are effective in enhancing school-related functions. In addition, the SRL intervention is effective in reducing behavioral problems of children with ASD. The SRL intervention was seen to be effective compared to the activity-based intervention with particular benefits for on-going learning and improvements. Therefore, the SRL intervention, as a cognitive approach using meaningful daily tasks, is recommended for children with ASD.

\section{Abbreviations}


ANOVA: Analysis of Variance

ASD: Autism Spectrum Disorders

BRIEF: Behavior Rating Inventory of Executive Functions

MANOVA: Multivariate Analysis of Variance

RCT: Randomized Controlled Trial

SFA: School Function Assessment

SRL: Self-Regulated Learning

VABS-2: Vineland Adaptive Behavior Scale, Second Edition

\section{Declarations}

\section{Ethics approval and consent to participate}

The study was granted ethical approval from the Western Sydney University Human Ethics Committee (H10816), the Economic Planning Unit of the Prime Minister's Department of Malaysia (UPE: 40I200I19/3128) and the National University of Malaysia (NN-162-2014).

The parents of the children were provided with an information sheet and the study was explained to them verbally, providing an opportunity for them to discuss any concerns prior to providing written consent. Informed written consent was obtained for all parents of the children before the start of the study. Confidentiality of information was maintained throughout the study.

\section{Consent for publication}

Not applicable.

\section{Availability of data and materials}

The datasets used and/or analyzed during the current study are available from the corresponding author on reasonable request.

\section{Competing interests}

All authors declare no potential conflicts of interest with respect to the research, authorship, and/or publication of this article.

\section{Funding}

The authors declare that there is no funding source.

\section{Authors' contributions}

FWY, KL, MB, SP and MK were involved in the study design. FWY and MK involved in data collection and supervision. FWY and KL completed the data processing and analysis. FWY, KL and MB interpreted the data as well as drafted the manuscript. All the authors have critically reviewed the manuscript read and approved the final manuscript. 
Authors would like to thank all the Ethical Committee for approving ethical clearance. We would like also to thank data collectors and study participants.

\section{References}

1. Isaksen J, Diseth TH, Scholberg S, Skjeldal OH. Autism Spectrum Disorders-Are they really epidemic? . European Journal of Pediatric Neurology. 2013;17(4):327-33.

2. American Psychiatric Association. Diagnostic and statistical manual of mental disorders (5th edition). Washington,DC: American Psychiatric Association; 2013.

3. Smith SA, Press B, Koenig KP, Kinnealey M. Effects of sensory integration intervention on self-stimulating and self-injurious behaviors. AJOT: American Journal of Occupational Therapy. 2005;59(4):418.

4. Achenbach TM, Rescorla LA. Manual for the ASEBA preschool forms \& profiles Burlington, VT: University of Vermont, Research Center for Children, Youth, \& Families; 2000.

5. Madigan S, Atkinson L, Laurin K, Benoit D. Attachment and internalizing behavior in early childhood: a meta-analysis. Developmental Psychology. 2013;49(4):672-89.

6. Sparrow SS, Cicchetti DV, Balla DA. Vineland adaptive behavior scales (2nd ed.). Circle Pines, MN: American Guidance Service; 2005.

7. Liu J. Childhood externalizing behavior: Theory and implications. Journal of Child and Adolescent Psychiatric Nursing. 2004(17):93103.

8. Wan Yunus F, Liu KPY, Bissett M, Penkala S. Sensory-Based Intervention for Children with Behavioral Problems: A Systematic Review. Journal of Autism and Developmental Disorders. 2015;45(11):3565-79.

9. Warren Z, McPheeters ML, Sathe N, Foss-Feig JH, Glasser A, Veenstra-VanderWeele J. A Systematic Review of Early Intensive Intervention for Autism Spectrum Disorders. Pediatrics. 2011;127(5):e1303-e11.

10. Reed P, Osborne LA, Corness M. Brief report: relative effectiveness of different home-based behavioral approaches to early teaching intervention. J Autism Dev Disord. 2007;37(9):1815-21.

11. Reichow B, Wolery M. Comprehensive synthesis of early intensive behavioral interventions for young children with autism based on the UCLA Young Autism Project model. Journal of Autism and Developmental Disorders. 2009;39(1):23-41.

12. Morgan RL, Salzberg CL. Effects of video-assisted training on employment-related skills of adults with severe mental retardation. Journal of Applied Behavior Analysis. 1992;25:365-83.

13. Nikopoulos CK, Keenan M. Using video modeling to teach complex social sequences to children with autism. Journal of Autism and Developmental Disorders. 2007;37(4):678-93.

14. Liu KPY, Balderi K, Leung TLF, Yue ASY, Lam NCW, Cheung JTY, et al. A Randomized Controlled Trial of Self-regulated Modified Constraint-induced Movement Therapy in Sub-acute Stroke Patients. European Journal of Neurology. 2016;0:1-10.

15. Liu KPY, Chan CCH. A pilot randomized controlled trial of self-regulation in promoting function in acute post-stroke patients. Archives of Physical Medicine and Rehabilitation. 2014;95(7):1262-7.

16. Liu KPY, Chan TMC, Lee LSW, Hui-Chan CWY. Self-regulatory learning and generalization for people with brain injury. Brain Injury. 2002;16(9):817-24.

17. Schraw G, Crippen KJ, Hartley K. Promoting Self-Regulation in Science Education: Metacognition as Part of a Broader Perspective on Learning. Research in Science Education. 2006;36:111-39.

18. Dinsmore DL, Alexander PA, Loughlin SM. Focusing the conceptual lens on metacognition, self-regulation, and self-regulated learning. Educ Psychol Rev. 2008(20):391-409.

19. Lamb SJ, Bibby PA, Wood DJ, Leyden G. An intervention programme for children with moderate learning difficulties. British Journal of Educational Psychology. 1998;68:493-504.

20. Hahn-Markowitz J, Manor I, Maeir A. Effectiveness of Cognitive-Functional (Cog-Fun) Intervention with Children with Attention Defecit Hyperactivity Disorder: A Pilot Study. American Journal of Occupational Therapy. 2011;65(4):384-92.

21. Suresh KP. An overview of randomization techniques: An unbiased assessment of outcome in clinical research. Journal of Human Reproductive Sciences. 2011;4(1):8-11.

22. Gioia GA, Isquith PK, Guy SC, Kenworthy L. Behavior Rating Inventory of Executive Function Florida: Psychological Assessment Resource, Inc; 1996.

23. Coster W, Deeney T, Haltiwanger J, Haley S. School function assessment (SFA). San Antonio: The Psychological Corporation; 1998. 
24. Wan Yunus F, Bissett M, Penkala S, Kadar M, Liu K. Malaysian parents' feedback on three proxy-rated assessments used in pediatric rehabilitation. Malaysian Journal of Public Health Medicine. 2018;18(1):64-9.

25. Pfeiffer BA, Koenig KP, Kinnealey M, Sheppard MC, Henderson L. Effectiveness of sensory integration interventions in children with autism spectrum disorders: a pilot study. American Journal of Occupational Therapy. 2011;65(1):76-85.

26. Cohen J. Statistical power for the behavioral sciences (2nd ed.). Hillsdale, NJ: Lawrence Erlbaum Associates; 1988.

27. Valentine JC, Cooper H. Effect size substantive interpretation guidelines: Issues in the interpretation of effect sizes. Washington, DC: What Works Clearinghouse; 2003.

28. Bandura A. Social foundations of though and action: A social-cognitive theory Englewood Cliffs, NJ: Prentice-Hall; 1986.

29. Bandura A. Self-efficacy: The exercise of control. New York Freeman; 1997.

30. Bandura A. Social cognitive theory in cultural context. Applied Psychology: An International Review. 2002;51(2):269-90.

31. Powers MD, Handelman. Behavioral assessment of severe developmental disabilities. Rockville, MD: Aspen Systems Corporation; 1984.

32. Bandura A. Social cognitive theory in cultural context. Applied Psychology: An International Review. 2002;51:269-90.

33. Miltenberger RG. Behavior modification. Principles and procedures (3rd Ed.). Pacific Grove, CA: Wadsworth; 2004.

34. Garretson H, Fein D, Waterhouse L. Sustained attention in autistic children. Journal of Autism and Developmental Disorders. 1990;20:101-14.

35. Buggey T, Toombs K, Gardener P, Cervetti M. Training responding behaviors in students with autism: Using videotaped self-modeling. Journal of Positive Behavior Interventions. 1999;1:205-14.

36. Nally B, Houlton B, Ralph S. Researches in brief: The management of television and video by parents of children with autism. Autism: The International Journal of Research and Practice. 2000;4:331-7.

37. Legoff DB. Use of LEGO as a therapeutic medium for improving social competence. Journal of autism and developmental Disorders. 2004;34:557-71.

38. Miller LJ, Coll JR, Schoen SA. A randomized controlled pilot study of the effectiveness of occupational therapy for children with sensory modulation disorder. American Journal of Occupational Therapy. 2007;61:228-38.

39. Liu KPY, Balderi K, Leung TLF, Yue ASY, Lam NCW, Cheung JTY, et al. A randomized controlled trial of self-regulated modified constraint induced movement therapy in sub-acute stroke patients. European Journal of Neurology. 2016;23:1351-60.

\section{Tables}

Table 1. Participant Baseline Characteristics 


\begin{tabular}{|c|c|c|c|c|c|c|c|}
\hline \multirow[t]{2}{*}{ Characteristics } & \multicolumn{3}{|c|}{$\begin{array}{l}\text { Control group } \\
(\mathrm{n}=20)\end{array}$} & \multicolumn{3}{|c|}{$\begin{array}{l}\text { Experimental group } \\
(\mathrm{n}=20)\end{array}$} & \multirow[t]{2}{*}{ Between-group differences $(p)$} \\
\hline & $\mathbf{N}(\%)$ & Mean & SD & $\mathbf{N}(\%)$ & Mean & SD & \\
\hline Age & & 7.45 & 1.19 & & 7.70 & 1.49 & $0.56^{\mathrm{a}}$ \\
\hline \multicolumn{8}{|l|}{ Gender } \\
\hline Male & 19 (95) & & & $15(75)$ & & & \multirow[t]{2}{*}{$0.77^{\mathrm{b}}$} \\
\hline Female & $1(5)$ & & & $5(25)$ & & & \\
\hline \multicolumn{8}{|l|}{ Ethnicity } \\
\hline Malay & $17(85)$ & & & $17(85)$ & & & \multirow[b]{2}{*}{$1.00^{\mathrm{b}}$} \\
\hline Chinese & $3(15)$ & & & $3(15)$ & & & \\
\hline \multicolumn{8}{|l|}{ Religion } \\
\hline Islam & $17(85)$ & & & $17(85)$ & & & \multirow{3}{*}{$0.55^{\mathrm{b}}$} \\
\hline Buddhism & $3(15)$ & & & $2(10)$ & & & \\
\hline Hinduism & & & & $1(5)$ & & & \\
\hline \multicolumn{8}{|l|}{ Intelligence } \\
\hline Normal & $5(25)$ & & & $4(20)$ & & & \multirow{3}{*}{$0.04^{b}$} \\
\hline Mild intellectual disability & & & & $11(55)$ & & & \\
\hline Moderate intellectual disability & $15(75)$ & & & $5(25)$ & & & \\
\hline \multicolumn{8}{|l|}{ Education } \\
\hline Preschool & $6(30)$ & & & $6(30)$ & & & \multirow[t]{2}{*}{$1.00^{\mathrm{b}}$} \\
\hline Primary school & $14(70)$ & & & $14(70)$ & & & \\
\hline \multicolumn{8}{|l|}{ Class placement } \\
\hline Special education & $13(65)$ & & & $10(50)$ & & & \multirow[t]{2}{*}{$0.34^{\mathrm{b}}$} \\
\hline Regular education & $7(35)$ & & & $10(50)$ & & & \\
\hline \multicolumn{8}{|c|}{ Current/previous intervention received } \\
\hline OT only & $7(35)$ & & & $5(25)$ & & & \\
\hline OT and ST & $12(60)$ & & & $14(70)$ & & & \\
\hline OT, PT and ST & $1(5)$ & & & & & & \multirow[b]{2}{*}{$0.48^{\mathrm{b}}$} \\
\hline None & & & & $1(5)$ & & & \\
\hline \multicolumn{8}{|c|}{ Current/previous intervention frequency } \\
\hline Weekly & $10(50)$ & & & $8(40)$ & & & \multirow{5}{*}{$0.14^{\mathrm{b}}$} \\
\hline Monthly & $8(40)$ & & & $4(20)$ & & & \\
\hline Every six months & $1(5)$ & & & $4(20)$ & & & \\
\hline Yearly & & & & $3(15)$ & & & \\
\hline None & $1(5)$ & & & $1(5)$ & & & \\
\hline VABS II score & & 18.60 & 5.14 & & 17.85 & 4.61 & $0.82^{\mathrm{a}}$ \\
\hline
\end{tabular}

OT = Occupational Therapy, PT $=$ Physiotherapy, ST $=$ Speech Therapy

a Analysis was perform using one-way ANOVA

${ }^{\mathrm{b}}$ Analysis was perform using Pearson Chi Square

Table 2. Results of the two groups and between-group comparisons 


\begin{tabular}{|c|c|c|c|c|c|c|c|c|c|c|c|c|c|c|}
\hline \multirow[t]{3}{*}{ Outcome measures } & \multicolumn{6}{|c|}{ Activity-based } & \multicolumn{8}{|c|}{ Self-regulated learning } \\
\hline & \multicolumn{2}{|c|}{$\begin{array}{l}\text { Pre- } \\
\text { intervention }\end{array}$} & \multicolumn{2}{|c|}{$\begin{array}{l}\text { Post- } \\
\text { intervention }\end{array}$} & \multicolumn{2}{|c|}{ Follow up } & \multicolumn{2}{|c|}{$\begin{array}{l}\text { Pre- } \\
\text { intervention }\end{array}$} & \multicolumn{2}{|c|}{$\begin{array}{l}\text { Post- } \\
\text { intervention }\end{array}$} & \multicolumn{2}{|c|}{ Follow up } & \multirow{2}{*}{$\begin{array}{l}\text { Pre- \& post- } \\
\text { intervention }\end{array}$} & \multirow{2}{*}{$\begin{array}{l}\text { Post- } \\
\text { intervention } \\
\& \text { follow up } \\
\text { Sig }(p)\end{array}$} \\
\hline & Mean & SD & Mean & SD & Mean & SD & Mean & SD & Mean & SD & Mean & SD & & \\
\hline VABS-2 & & & & & & & & & & & & & & \\
\hline $\begin{array}{l}\text { Maladaptive } \\
\text { Behaviour Index }\end{array}$ & 19.20 & 1.20 & 18.80 & 1.40 & 18.8 & 1.40 & 18.90 & 1.12 & 17.50 & 1.28 & 17.40 & 1.23 & 0.65 & $0.00 * *$ \\
\hline BRIEF & & & & & & & & & & & & & & \\
\hline $\begin{array}{l}\text { Behaviour } \\
\text { Regulation Index } \\
\text { (BRI) }\end{array}$ & 61.65 & 9.86 & 60.20 & 11.20 & 59.95 & 11.22 & 63.90 & 12.41 & 54.10 & 9.05 & 53.65 & 8.88 & 0.81 & 0.16 \\
\hline $\begin{array}{l}\text { Metacognition Index } \\
\text { (MI) }\end{array}$ & 62.35 & 10.47 & 58.50 & 10.71 & 58.50 & 10.71 & 65.70 & 11.47 & 52.05 & 10.99 & 51.90 & 10.94 & 0.88 & 0.15 \\
\hline SFA & & & & & & & & & & & & & & \\
\hline $\begin{array}{l}\text { Functional } \\
\text { Communication }\end{array}$ & 44.10 & 13.23 & 44.30 & 13.21 & 44.30 & 13.21 & 56.85 & 22.29 & 63.20 & 20.21 & 63.20 & 20.21 & $0.01^{* *}$ & $0.00^{* * *}$ \\
\hline $\begin{array}{l}\text { Memory and } \\
\text { Understanding }\end{array}$ & 50.00 & 8.63 & 51.35 & 8.43 & 51.35 & 8.43 & 59.05 & 15.25 & 73.45 & 13.56 & 73.45 & 13.56 & $0.00^{* * *}$ & $0.00^{* * *}$ \\
\hline $\begin{array}{l}\text { Following Social } \\
\text { Conversations }\end{array}$ & 46.60 & 10.89 & 46.60 & 10.89 & 46.60 & 10.89 & 50.30 & 12.21 & 56.05 & 12.45 & 56.05 & 12.45 & 0.20 & $0.04^{*}$ \\
\hline $\begin{array}{l}\text { Compliance with } \\
\text { Adult Directives and } \\
\text { School Rules }\end{array}$ & 54.05 & 9.25 & 57.35 & 11.62 & 57.35 & 11.62 & 56.45 & 11.44 & 65.20 & 14.73 & 65.20 & 14.73 & 0.38 & 0.17 \\
\hline $\begin{array}{l}\text { Task } \\
\text { Behavior/Completion }\end{array}$ & 51.60 & 13.39 & 53.55 & 13.16 & 53.55 & 13.16 & 55.90 & 8.58 & 62.40 & 9.46 & 62.60 & 9.65 & 0.18 & 0.06 \\
\hline Positive Interaction & 52.65 & 7.42 & 52.75 & 7.37 & 52.75 & 7.37 & 57.90 & 8.55 & 62.10 & 7.46 & 62.25 & 7.62 & $0.05^{*}$ & $0.00^{* * *}$ \\
\hline Behavior Regulation & 49.15 & 15.14 & 49.6 & 15.17 & 49.60 & 15.17 & 51.45 & 9.30 & 62.15 & 13.31 & 62.15 & 13.31 & 0.16 & $0.02^{*}$ \\
\hline $\begin{array}{l}\text { Personal Care } \\
\text { Awareness }\end{array}$ & 50.30 & 15.40 & 50.45 & 15.39 & 50.45 & 15.39 & 51.50 & 13.71 & 55.85 & 13.51 & 55.85 & 13.51 & 0.71 & 0.45 \\
\hline Safety & 39.35 & 15.86 & 39.50 & 15.98 & 39.50 & 15.98 & 44.00 & 12.00 & 49.30 & 12.34 & 49.30 & 12.34 & 0.23 & 0.07 \\
\hline
\end{tabular}

VABS-2 = Vineland Adaptive Behavior Scale, Second Edition; BRIEF = Behavior rating inventory of Executive Functions;

SFA $=$ School Function Assessment

$* * * \mathrm{p}<0.001, * * \mathrm{p}<0.01, * \mathrm{p}<0.05$

Table 3. Results of the within-group comparisons 


\begin{tabular}{|c|c|c|c|c|c|c|c|c|c|c|}
\hline \multirow[t]{3}{*}{ Outcome measures } & \multirow[t]{3}{*}{ Groups } & \multirow{2}{*}{\multicolumn{3}{|c|}{$\begin{array}{c}\text { Repeated Measure } \\
\text { MANOVA }\end{array}$}} & \multicolumn{6}{|c|}{ Post Hoc Tukey Test } \\
\hline & & & & & \multicolumn{3}{|c|}{ Pre-Post } & \multicolumn{3}{|c|}{ Post-Follow-Up } \\
\hline & & $F$ & Sig & $D^{2}$ & $\mathrm{f}$ & sig & $D^{2}$ & $\mathrm{f}$ & sig & $D^{2}$ \\
\hline \multicolumn{11}{|l|}{ VABS-2 } \\
\hline \multirow[t]{2}{*}{ Maladaptive Behavior Index } & $\begin{array}{l}\text { Self-regulated } \\
\text { learning }\end{array}$ & 50.74 & $0.00^{* * *}$ & 0.73 & 50.32 & $0.00^{* * *}$ & 0.726 & 1.00 & 0.33 & 0.05 \\
\hline & Activity-based & 3.62 & $0.04^{*}$ & 0.16 & 3.62 & 0.07 & 0.16 & t & $\dagger$ & $\dagger$ \\
\hline \multicolumn{11}{|l|}{ BRIEF } \\
\hline \multirow[t]{2}{*}{ Behavior Regulation Index (BRI) } & $\begin{array}{l}\text { Self-regulated } \\
\text { learning }\end{array}$ & 19.63 & $0.00^{* * *}$ & 0.51 & 18.98 & $0.00^{* * *}$ & 0.500 & 2.08 & 0.17 & 0.10 \\
\hline & Activity-based & 1.60 & 0.22 & 0.08 & 1.43 & 0.25 & 0.07 & 1.00 & 0.33 & 0.05 \\
\hline \multirow[t]{2}{*}{ Metacognition Index (MI) } & $\begin{array}{l}\text { Self-regulated } \\
\text { learning }\end{array}$ & 65.73 & $0.00^{* * *}$ & 0.78 & 61.65 & $0.00^{* * *}$ & 0.764 & 1.00 & 0.33 & 0.05 \\
\hline & Activity-based & 6.16 & $0.01^{* *}$ & 0.25 & 6.16 & $0.02^{*}$ & 0.25 & t & $\dagger$ & $\dagger$ \\
\hline \multicolumn{11}{|l|}{ SFA } \\
\hline \multirow[t]{2}{*}{ Functional Communication } & $\begin{array}{l}\text { Self-regulated } \\
\text { learning }\end{array}$ & 3.35 & $0.05^{*}$ & 0.15 & 3.35 & 0.08 & 0.150 & $\dagger$ & $\dagger$ & $\dagger$ \\
\hline & Activity-based & 1.00 & 0.38 & 0.05 & 1.00 & 0.33 & 0.05 & $\dagger$ & $\dagger$ & $\dagger$ \\
\hline \multirow[t]{2}{*}{ Memory and Understanding } & $\begin{array}{l}\text { Self-regulated } \\
\text { learning }\end{array}$ & 23.05 & $0.00^{* * *}$ & 0.55 & 23.05 & $0.00^{* * *}$ & 0.548 & $\dagger$ & $\dagger$ & $\dagger$ \\
\hline & Activity-based & 5.39 & $0.01^{* *}$ & 0.22 & 5.39 & $0.03^{*}$ & 0.22 & $\dagger$ & $\dagger$ & $\dagger$ \\
\hline \multirow[t]{2}{*}{ Following Social Conversation } & $\begin{array}{l}\text { Self-regulated } \\
\text { learning }\end{array}$ & 29.51 & $0.00^{* * *}$ & 0.61 & 29.51 & $0.00^{* * *}$ & 0.608 & $\dagger$ & $\dagger$ & $\dagger$ \\
\hline & Activity-based & $\dagger$ & t & t & $\dagger$ & $t$ & $\dagger$ & $\dagger$ & $\dagger$ & $\dagger$ \\
\hline \multirow[t]{2}{*}{$\begin{array}{l}\text { Compliance with Adult Directives and School } \\
\text { Rules }\end{array}$} & $\begin{array}{l}\text { Self-regulated } \\
\text { learning }\end{array}$ & 11.71 & $0.00^{* * *}$ & 0.38 & 11.71 & $0.00^{* * *}$ & 0.381 & $\dagger$ & $\dagger$ & $\dagger$ \\
\hline & Activity-based & 16.15 & $0.00^{* * *}$ & 0.46 & 16.15 & $0.00^{* *}$ & 0.46 & $\dagger$ & $\dagger$ & $\dagger$ \\
\hline \multirow[t]{2}{*}{ Task Behavior/ Completion } & $\begin{array}{l}\text { Self-regulated } \\
\text { learning }\end{array}$ & 13.76 & $0.00^{* * *}$ & 0.42 & 13.66 & $0.00^{* * *}$ & 0.418 & 1.00 & 0.33 & 0.05 \\
\hline & Activity-based & 10.55 & $0.00^{* * *}$ & 0.36 & 10.55 & $0.00^{* *}$ & 0.36 & † & $t$ & $\dagger$ \\
\hline \multirow[t]{2}{*}{ Positive Interaction } & $\begin{array}{l}\text { Self-regulated } \\
\text { learning }\end{array}$ & 30.07 & $0.00^{* * *}$ & 0.61 & 30.03 & $0.00^{* * *}$ & 0.612 & 1.00 & 0.33 & 0.05 \\
\hline & Activity-based & 2.11 & 0.14 & 0.10 & 2.11 & 0.16 & 0.10 & $\dagger$ & $\dagger$ & $\dagger$ \\
\hline \multirow[t]{2}{*}{ Behavior Regulation } & $\begin{array}{l}\text { Self-regulated } \\
\text { learning }\end{array}$ & 21.73 & $0.00^{* * *}$ & 0.53 & 21.73 & $0.00^{* * *}$ & 0.534 & $\dagger$ & $\dagger$ & $\dagger$ \\
\hline & Activity-based & 1.00 & 0.38 & 0.05 & 1.00 & 0.33 & 0.05 & $\dagger$ & $\dagger$ & $\dagger$ \\
\hline \multirow[t]{2}{*}{ Personal Care Awareness } & $\begin{array}{l}\text { Self-regulated } \\
\text { learning }\end{array}$ & 1.07 & 0.35 & 0.05 & 1.07 & 0.32 & 0.053 & $\dagger$ & $\dagger$ & $\dagger$ \\
\hline & Activity-based & 1.00 & 0.38 & 0.05 & 1.00 & 0.33 & 0.05 & $\dagger$ & $\dagger$ & $\dagger$ \\
\hline \multirow[t]{2}{*}{ Safety } & $\begin{array}{l}\text { Self-regulated } \\
\text { learning }\end{array}$ & 22.7 & $0.00^{* * *}$ & 0.54 & 22.7 & $0.00^{* * *}$ & 0.544 & $\dagger$ & $\dagger$ & $\dagger$ \\
\hline & Activity-based & 1.00 & 0.38 & 0.05 & 1.00 & 0.33 & 0.05 & $\dagger$ & $\dagger$ & $\dagger$ \\
\hline
\end{tabular}

VABS-2 = Vineland Adaptive Behavior Scale, Second Edition; BRIEF = Behavior rating inventory of Executive Functions; SFA = School Function Assessment

${ }^{* * *} \mathrm{p}<0.001, * * \mathrm{p}<0.01, * \mathrm{p}<0.05 ; \dagger=$ Analyses cannot be performed (no changes occurred; the results are similar); $\square^{2}=$ partial eta square

\section{Figures}




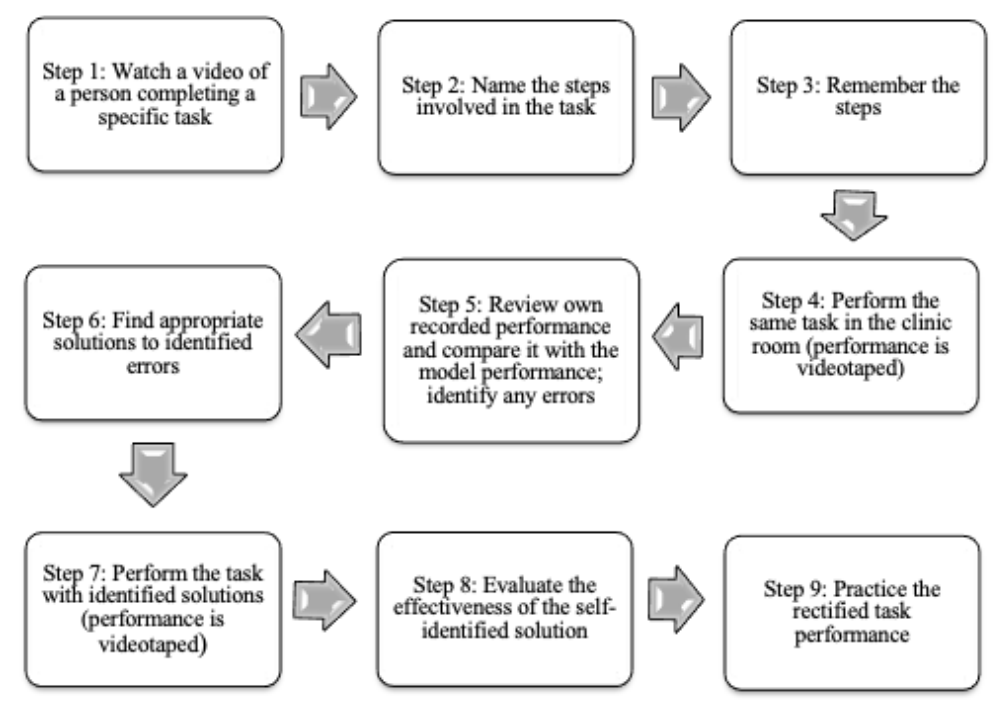

The daily and school tasks included were:

1 Picking up rubbish and throwing it in the rubbish bag

2 Pouring water in a water bottle for school

3 Tidying up after play activity

4 Organizing a pencil case for school

5 Packing a lunchbox for school

6 Organizing a backpack for school

7 Cleaning up after meals

8 Cutting along lines on a page using scissors

9 Gluing and pasting items on paper

10 Placing books on a bookshelf

11 Erasing pencil marks from books

12 Writing letters between lines in a book

13 Tidying a clothing cupboard

14 Making a sandwich for school

15 Buying snacks from the school canteen

\section{Figure 1}

Step-by-step procedure for the Self-Regulation Learning intervention

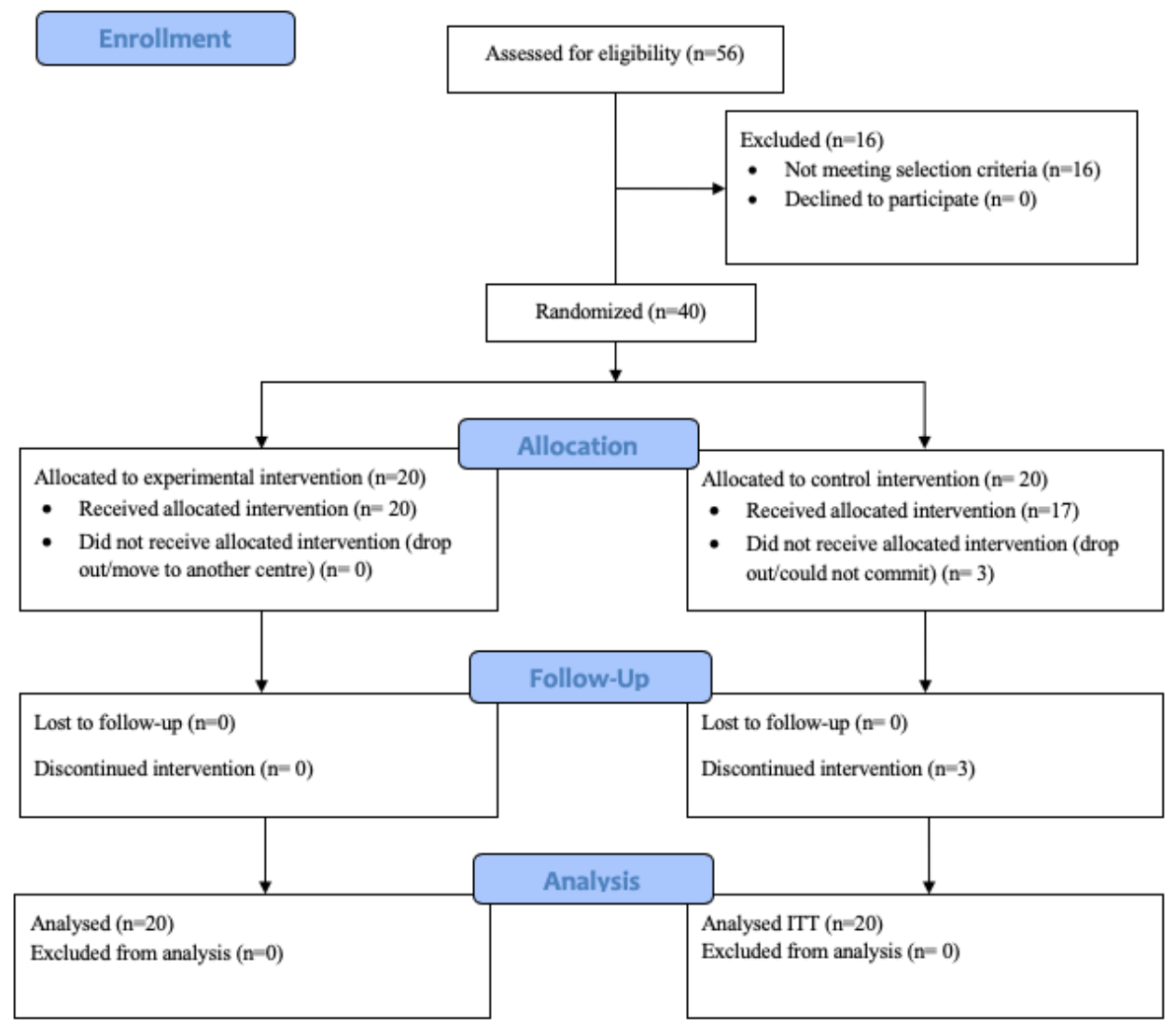


Figure 2

Consort flow diagram

Page 14/ 14 